STOMACH

\title{
Decreased Helicobacter pylori associated gastric carcinogenesis in mice lacking inducible nitric oxide synthase
}

\author{
K T Nam, S-Y Oh, B Ahn, Y B Kim, D D Jang, K-H Yang, K-B Hahm, D-Y Kim
}

Gut 2004;53:1250-1255. doi: 10.1136/gut.2003.030684

See end of article for authors' affiliations

.....................

Correspondence to: Professor D-Y Kim, Department of Veterinary Pathology, College of Veterinary Medicine, Seoul National University, San 56-1, Shillim-dong, Kwanak-gu, Seoul'151742, Korea; daeyong@ plaza.snu.ac.kr

Revised version received 26 January 2004

Accepted for publication 19 February 2004
Background and aims: Overproduction of nitric oxide via inducible nitric oxide synthase (iNOS) is suggested to be a significant pathogenic factor in Helicobacter pylori induced gastritis. The purpose of this study was to examine the role of iNOS in $\mathrm{H}$ pylori associated gastric carcinogenesis.

Methods: Two types of mice were used in this study: iNOS deficient mice (iNOS-/-) and wild-type littermates. Gastric cancer was generated in mice using a combination treatment comprising N-methyl- $N$ nitrosourea administration and $\mathrm{H}$ pylori infection. Fifty weeks after treatment, tumours in gastric tissues from both types of mice were examined using histopathology, immunohistochemistry, and immunoblotting for iNOS and 3-nitrotyrosine.

Results: The overall incidence of gastric cancer at week 50 was significantly lower in iNOS - / - compared with iNOS wild-type mice $(p<0.05)$. When analysed according to tumour pathology, the incidence of gastric adenocarcinoma was significantly lower in iNOS-/- compared with iNOS wild-type mice $(p<0.05)$. Immunostaining for iNOS was clearly observed in adenocarcinoma cells of iNOS wild-type mice, and was characterised by a strong cytoplasmic expression pattern. 3-Nitrotyrosine was expressed mostly in the area of the lamina propria of gastritis and adenoma lesions in iNOS wild-type mice. Immunoblotting analyses showed that iNOS and 3-nitrotyrosine were also expressed in both adenoma and adenocarcinoma tissues from iNOS wild-type mice. iNOS and 3-nitrotyrosine expression was greater in tumour tissues than in non-tumour tissues.

Conclusions: These findings suggest that iNOS contributes to $\mathrm{H}$ pylori associated gastric carcinogenesis in mice.
G astric adenocarcinoma is one of the most prevalent malignant neoplasms worldwide, particularly in Eastern Asia, including Korea and Japan. ${ }^{12}$ Development of gastric cancer is believed to occur over a long period of time and to involve a number of events, with the primary aetiological determinants being exposure to chemical carcinogens and/or Helicobacter pylori infection. ${ }^{3} H$ pylori is the most important aetiological agent of chronic active gastritis and peptic ulcers. Moreover, $H$ pylori infection has been identified as a human carcinogen based mainly on epidemiological evidence, ${ }^{4}$ and it is possible that chronic inflammation induced by $H$ pylori infection increases the risk of gastric cancer.

It has been proposed that formation of reactive oxygen species (ROS) as a result of neutrophil infiltration in response to $H$ pylori infection can injure epithelial cells and damage their DNA, which may contribute to the initiation and promotion of tumours. Apart from ROS, another important mediator in chronic inflammatory processes after $H$ pylori infection is nitric oxide (NO), which is produced by gastric epithelial and non-epithelial cells from L-arginine via a family of three distinct nitric oxide synthase (NOS) isoforms. ${ }^{56}$ Two NOS isoforms are constitutively expressed and are calcium dependent-namely, eNOS (expressed in vascular endothelial cells) and nNOS (expressed in neurones of the central and peripheral nervous system). The third isoform, iNOS, is inducible and calcium independent, and is expressed in response to bacterial endotoxins and cytokines to cause sustained NO release. iNOS can produce larger amounts of NO than either eNOS or nNOS. NO overproduction is associated with the pathogenesis of a variety of disorders including cancer, and NO also stimulates tumour angiogenesis $^{7}$ as well as vascular permeability in solid tumours. ${ }^{8}$

Increased iNOS activity has been observed in patients with chronic gastritis and precancerous lesions, as well as in gastric adenocarcinoma patients, ${ }^{9}{ }^{10}$ and it has been reported that iNOS levels were significantly reduced after eradication of $H$ pylori. ${ }^{11}$ iNOS expression in the gastric mucosa is significantly higher in $H$ pylori positive gastric cancer patients than in $H$ pylori negative patients. ${ }^{12}$ These observations suggest that overproduction of the iNOS enzyme in the gastric mucosa infected with $H$ pylori may contribute to the carcinogenesis of gastric cancer. However, high induction of iNOS with subsequent overproduction of NO involves complex responses in tissues which has led to some debate regarding the effect of iNOS on carcinogenesis. For example, some studies have reported protection after inhibition of iNOS $^{13-15}$ while others have reported exacerbation of the carcinogenic process. ${ }^{16}{ }^{17}$

Advances in recombinant DNA technology have permitted the development of mice that specifically lack the capacity to express the iNOS gene. ${ }^{18}$ These iNOS $-/-$ mice can produce NO constitutively but are unable induce NO production via the iNOS enzyme. The aim of the present study was to examine the role of inducible NO production in $H$ pylori associated gastric carcinogenesis. To achieve this we used

Abbreviations: NO, nitric oxide; NOS, NO synthase; iNOS, inducible NOS; eNOS, endothelial NOS; nNOS, neuronal NOS; MNU, $\mathrm{N}$-methyl- $\mathrm{N}$-nitrosourea; ROS, reactive oxygen species; $\mathrm{CFU}$, colony forming unit; $A G$, aminoguanidine 
iNOS $-/-$ and their wild-type littermates in a previously published mouse model of $H$ pylori associated gastric cancer. ${ }^{19}$

\section{MATERIALS AND METHODS \\ Mice}

Male C57BL/6-Nos2 ${ }^{\text {tmlLau }}$ (iNOS - /- ) mice (iNOS-/- ) and wild-type littermates (iNOS wild-type) were obtained from Jackson Laboratory (Bar Harbor, Maine, USA) at five weeks of age. Mice were handled in an accredited Korean FDA animal facility in accordance with AAALAC International Animal Care policies (Accredited Unit-Korea Food and Drug Administration: Unit Number-000996). All mice were given a standard pellet chow diet (CRF-1; Oriental Yeast Co., Ltd, Tokyo, Japan) ad libitum and were maintained under specific pathogen free conditions.

\section{Chemicals and bacteria}

$N$-methyl- $N$-nitrosourea (MNU) (Sigma Chemical Co., St Louis, Missouri, USA) solutions were freshly prepared twice a week by dissolving $200 \mathrm{mg} / \mathrm{l} \mathrm{MNU}$ in distilled water. Where indicated, mice were given the $200 \mathrm{mg} / \mathrm{l} \mathrm{MNU}$ solution ad libitum in light shielded bottles in place of drinking water. Mouse adapted $H$ pylori (SS1) were inoculated on Brucella agar plates (Becton Dickinson, Cockysville, Maryland, USA) containing $10 \%$ heat inactivated fetal bovine serum and Skirrow medium (Difco, Detroit, Michigan, USA). They were kept at $37^{\circ} \mathrm{C}$ under microaerobic conditions using GasPak jars (Difco) and CampyPaks (Becton Dickinson). After 24 hours of fasting, a $0.1 \mathrm{ml}$ suspension of $H$ pylori containing $1 \times 10^{9}$ colony forming units $(\mathrm{CFU}) / \mathrm{ml}$ was administered by intragastric intubation.

\section{Study design}

Mice were divided randomly into two groups (fig 1). Both iNOS wild-type $(\mathrm{n}=25)$ and iNOS $-/-(\mathrm{n}=30)$ mice were given drinking water containing MNU (200 mg/l) every second week for 10 weeks. One week after completing MNU treatment, both iNOS-/- and iNOS wild-type mice were inoculated with $H$ pylori three times every other day. Mice were sacrificed 38 weeks after the first inoculation with H pylori.

\section{Histopathological examination}

Immediately after sacrifice, mouse stomachs were opened along the greater curvature. The number as well as the length (diameter) of the tumours in the stomach were measured. A record was kept of the size and number of tumours counted, with a diagnosis being made after the final histopathological examination. The excised stomachs were fixed in neutral buffered $10 \%$ formalin and cut into approximately six strips, processed by standard methods, embedded in paraffin, sectioned at $4 \mu \mathrm{m}$, and stained with haematoxylin and eosin. Histopathological examination was used to classify the characteristics of the tumours based on both the histopathological and cytological criteria reported by Leininger and
Jokinen. ${ }^{20}$ After diagnosing the tumour, tumour incidence and multiplicity were calculated. Samples of tumours and normal stomach tissue were quickly frozen in liquid nitrogen for western blot analyses.

\section{Identification of $\boldsymbol{H}$ pylori in gastric mucosa}

To confirm $H$ pylori infection, approximately $3 \mathrm{~mm}^{2}$ samples of stomach mucosa from the greater curvature containing both fundic and pyloric glands were transferred to $1.0 \mathrm{ml}$ of sterile $0.1 \mathrm{M}$ phosphate buffered saline, homogenised, and plated on selective trypticase soy agar $/ 5 \%$ sheep blood plates containing vancomycin $(20 \mathrm{mg} / \mathrm{ml})$, nalidixic acid ( $10 \mathrm{mg} /$ $\mathrm{ml})$, bacitracin $(30 \mathrm{mg} / \mathrm{ml})$, and amphotericin $\mathrm{B}(2 \mathrm{mg} / \mathrm{ml})$ (Sigma Chemical Co.), and grown for 3-5 days. Colonies were identified by characteristic Gram stain morphology, and by urease, catalase, and oxidase activity. Another $3 \mathrm{~mm}^{2}$ sample from the antrum was placed into the gel of a rapid urease test kit (CLO test; Trimed, Delta West, Australia) and left for six hours at room temperature to test for urease activity. The presence of $H$ pylori in the gastric pit was further confirmed by Warthin-Starry staining.

\section{iNOS and 3-nitrotyrosine immunohistochemistry}

Immunohistochemical identification of iNOS and 3nitrotyrosine protein expression was performed on replicate sections of stomach tissues. Sections were mounted on siliconised slides (Dako, Denmark), dewaxed, rehydrated, and endogenous peroxidase activity quenched using hydrogen peroxide $(3 \% \mathrm{v} / \mathrm{v})$. After washing in double distilled water, sections were subjected to microwave antigen retrieval in a $0.01 \mathrm{M}$ citrate buffer, $\mathrm{pH} 6.0$, for 10 minutes at $750 \mathrm{~W}$. Sections were allowed to cool and were then blocked with a blocking serum for one hour. Slides were incubated with either polyclonal antibody against iNOS (1:400) (Cayman Chemical, Michigan, USA) or monoclonal antibody against 3nitrotyrosine (1:50) (Upstate Biotechnology, Lake Placid, New York, USA) overnight at $4^{\circ} \mathrm{C}$. Immunoreaction complexes were detected using the avidin-biotin affinity system (Santa Cruz Biotechnology, California, USA) and visualised with 3,3-diaminobenzidine tetrahydrochloride as the chromogen. Sections were counterstained with Mayer's haematoxylin and examined under a light microscope. "Control" sections were produced by excluding iNOS or 3-nitrotyrosine antibodies during analysis.

\section{Western blotting for iNOS and 3-nitrotyrosine}

Frozen tissue regions from the glandular stomach diagnosed as non-tumour, adenoma, or adenocarcinoma were separately homogenised in RIPA buffer (10 mM Tris (pH 7.6), $1 \mathrm{mM}$ EDTA (pH 8.0), $100 \mathrm{mM} \mathrm{NaCl}, 1 \mu \mathrm{g} / \mathrm{Me}$ aprotinin, and $100 \mu \mathrm{g} / \mathrm{Me}$ PMSF (all from Sigma Chemical Co.)). Protein concentration was measured using a Bio-Rad Protein Assay kit (Bio-Rad Laboratories, Hercules, California, USA). Extracted proteins (40 $\mu \mathrm{g} / \mathrm{lane})$ were resolved by sodium dodecyl sulphate-polyacrylamide gel electrophoresis and

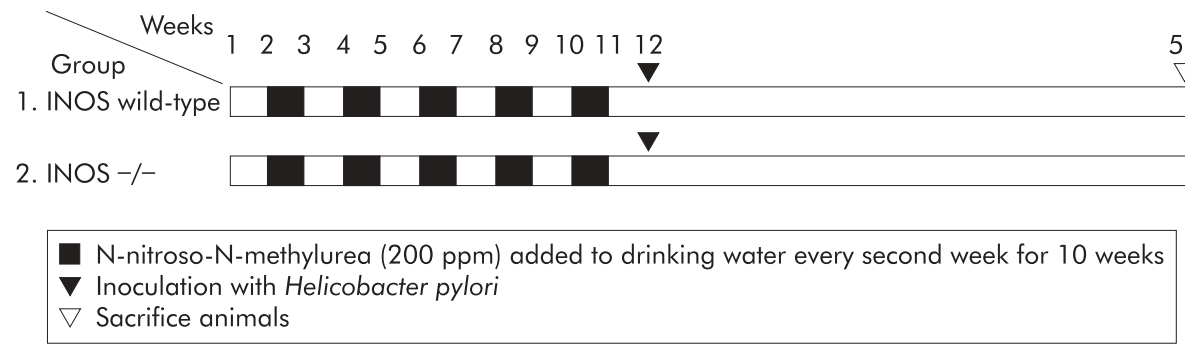

Figure 1 Study design. Mice were randomised to one of two groups and treated with $N$-methyl- $N$-nitrosourea (MNU) plus Helicobacter pylori. Group 1 = wild-type littermates (C57BL/6 background); group 2 =iNOS $-/-$. 
Table 1 Incidence and multiplicities of glandular stomach tumours in mice

\begin{tabular}{|c|c|c|c|c|c|}
\hline Group & $\begin{array}{l}\text { Total No } \\
\text { of mice }\end{array}$ & $\begin{array}{l}\text { Effective No } \\
\text { of mice }\end{array}$ & $\begin{array}{l}\text { No of } \\
\text { dead (\%) }\end{array}$ & $\begin{array}{l}\text { No of tumour bearing } \\
\text { mice (\% incidence) }\end{array}$ & $\begin{array}{l}\text { Tumour } \\
\text { multiplicity† }\end{array}$ \\
\hline $\begin{array}{l}1=\text { iNOS wild-type } \\
2=\text { iNOS }-/-\end{array}$ & 25 & 22 & $3(12)$ & $16(72.7)$ & $1.25(0.14)$ \\
\hline $2=$ iNOS $-1-$ & 30 & 29 & 1 (3.3) & $9(31.0)^{*}$ & $1.25(0.11)$ \\
\hline
\end{tabular}

transferred to PVDF membranes. Membranes were incubated overnight at $4{ }^{\circ} \mathrm{C}$ with either an iNOS polyclonal antibody (1:500) or a 3-nitrotyrosine monoclonal antibody (1:1000), and then incubated for 45 minutes with a secondary antibody (Santa Cruz). Following incubation with the secondary antibody, blots were washed three times with phosphate buffered saline $/ 0.1 \%$ Tween-20 and developed with a commercial chemiluminescence detection kit (Amersham Biosciences UK Ltd, Little Chalfont, Buckinghamshire, UK). Protein expression was quantified using a Bio-Rad Imaging Densitometer system Model GS690 (Bio-Rad Laboratories).

\section{Statistical analysis}

Data were analysed using the JMP software package (version 4.0) (SAS Institute, Cary, North Carolina, USA) on an IBM computer. Stomach tumour incidence data were analysed using a $\chi^{2}$ test. Other data were compared using the Dunnett $t$ test after ANOVA analysis. For all comparisons, probability values less than $5 \%(p<0.05)$ were considered statistically significant.

\section{RESULTS}

\section{Bacterial colonisation}

At week 50, stomachs were removed and all mice from both groups showed positive $H$ pylori colonisation, as determined by direct bacterial culture and rapid urease tests. The mean (SEM) number of CFU recovered from mice inoculated orally with $H$ pylori SSl was $2.32(0.21) \times 10^{5} / \mathrm{mg}$ gastric tissue. Warthin-Starry staining showed numerous spiral bacteria in gastric cells along the length of the gastric pits in both the antrum and body of all animals inoculated with $H$ pylori.

\section{Incidence and multiplicity of stomach tumours}

Tumour incidence and multiplicities are summarised in table 1 . The body weight of iNOS wild-type and iNOS-/mice was similar throughout all experiments. Tumours were found mostly in the pyloric mucosa adjacent to the fundic region. Macroscopically, most tumours showed a polypoid growth pattern similar to type I stomach cancers in humans (fig 2), and some were sessile. Tumour incidences at week 50 were $72.7 \%(16 / 22)$ and $31.0 \%(9 / 29)$ in iNOS wild-type and iNOS $-/-$ mice, respectively, and this difference was statistically significant $(\mathrm{p}<0.05)$.

There were significant differences in tumour pathologies between the two types of mice. In wild-type mice, gastric adenomas constituted $27.3 \%$ and adenocarcinoma $45.5 \%$ of all tumours, while in iNOS $-/-$ mice the incidence of gastric adenoma and adenocarcinoma was $10.3 \%$ and $20.7 \%$, respectively. Collectively, the incidence of gastric adenocarcinomas was significantly lower in iNOS $-/-$ mice compared with iNOS wild-type mice (table 2). These findings strongly suggest that the absence of iNOS significantly suppresses chemical carcinogen and $H$ pylori associated gastric carcinogenesis in mice.

\section{iNOS and 3-nitrotyrosine protein expression in stomach tissue}

iNOS protein expression was independently evaluated by three pathologists using immunohistochemical techniques. As expected, there was no iNOS detected in epithelial or stromal cells of gastric mucosal tissue from iNOS $-/-$ mice. In contrast, iNOS was strongly expressed in the cytoplasm of adenocarcinoma cells from iNOS wild-type mice, especially in cells on the luminal side (fig 3A). Elsewhere, iNOS expression in adenocarcinomas of wild-type mice was limited to small numbers of fibroblasts and inflammatory cells that had infiltrated the stroma (fig 3B).

Immunohistochemical analysis was also performed in order to determine 3-nitrotyrosine expression. 3-Nitrotyrosine was found to be strongly expressed in the cytoplasm of infiltrating chronic inflammatory cells such as macrophages, some lymphocytes, and some fibroblasts in tissues from iNOS wild-type mice with gastritis and adenomas (fig 4). In contrast, 3-nitrotyrosine was not detectable in such cells in tissue from iNOS $-/-$ mice. Negative controls showed no positive immunoexpression in tissue sections when the primary antibody step was omitted.
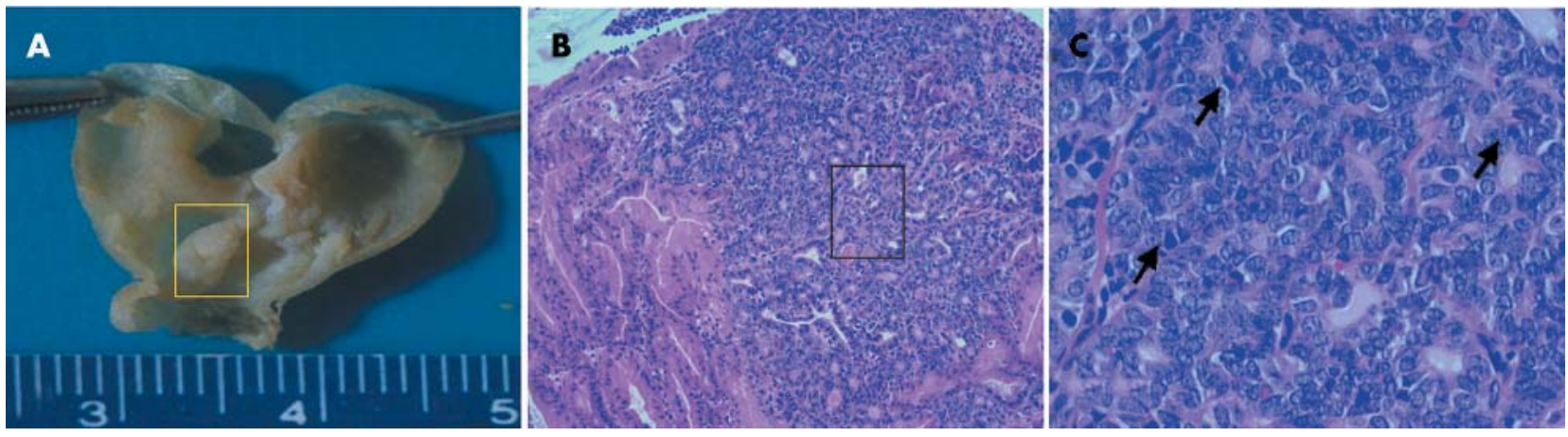

Figure 2 Macroscopic (A) and microscopic (B, C) appearance of gastric cancers in wild-type mice. (A) Multiple polypoid tumours are evident in the stomachs of inducible nitric oxide synthase (iNOS) wild-type mice after $N$-methyl- $N$-nitrosourea and Helicobacter pylori treatment. (B) The polypoid mass shows an intramucosal adenocarcinoma with disseminated neoplastic glandular formations (original magnification $\times 100$ ). (C) The adenocarcinoma shows an atypical irregular glandular hyperplasia with cribriform appearance, which is composed of pleomorphic atypical tumour cells with oval to round nuclei, with many mitotic figures apparent (arrow) (original magnification $\times 400$ ). 
Table 2 Incidence of glandular stomach tumours according to histopathological findings

\begin{tabular}{lllll}
\hline Group & $\begin{array}{l}\text { Effective No of } \\
\text { mice }\end{array}$ & $\begin{array}{l}\text { No of tumour } \\
\text { bearing mice }\end{array}$ & $\begin{array}{l}\text { Gastric } \\
\text { adenoma (\%) }\end{array}$ & $\begin{array}{l}\text { Gastric } \\
\text { adenocarcinoma (\%) }\end{array}$ \\
\hline $\begin{array}{l}1=\text { iNOS wild-type } \\
2=\text { iNOS }-/-\end{array}$ & 22 & 16 & $6(27.3)$ & $10(45.5)$ \\
\hline *Significantly different from group $1(p<0.05)$. & 13 & $3(10.3)$ & $6(20.7)^{*}$ \\
\hline
\end{tabular}

Western blotting using gastric mucosa homogenates was performed in order to quantitatively analyse iNOS and 3-nitrotyrosine levels in non-tumour and tumour (adenoma and adenocarcinoma) tissue from wild-type mice. We found that both proteins were expressed in homogenates derived from non-tumour, adenoma, and adenocarcinoma tissue (fig 5A). However, iNOS expression was significantly higher in adenoma and adenocarcinoma tissues compared with nontumour tissues $(\mathrm{p}<0.05)$ (fig $5 \mathrm{~B})$. Similarly, 3-nitrotyrosine protein expression was significantly higher in adenoma and adenocarcinoma homogenates compared with non-tumour homogenates $(\mathrm{p}<0.05)$ (fig $5 \mathrm{C})$.
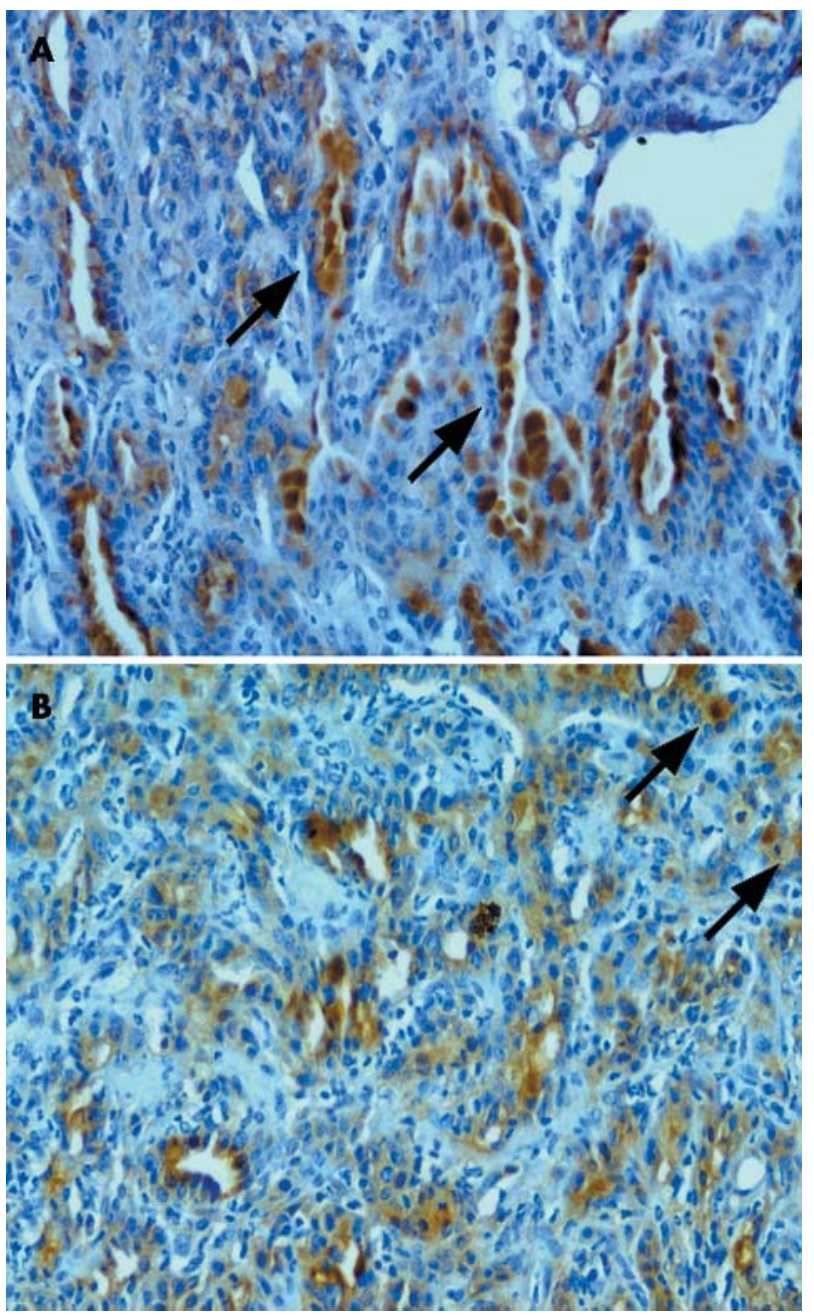

Figure 3 Immunohistochemical staining for inducible nitric oxide synthase (iNOS) in adenocarcinomas of wild-type mice. (A) Positive staining for iNOS was clearly observed in iNOS wild-type adenocarcinoma epithelial cells which was characterised by a strong intense cytoplasmic expression pattern. Epithelial staining was particularly strong on the luminal surfaces (arrow) of the carcinoma cells (original magnification $\times 200$ ). (B) iNOS immunoreactivity in adenocarcinoma of wild-type mice was also occasionally observed in inflammatory cells (arrow) in the stroma (original magnification $\times 200$ ).

\section{DISCUSSION}

The major purpose of this study was to better understand the influence of iNOS expression on the development of $H$ pylori associated gastric cancer. To achieve this aim, we used iNOS gene deficient mice and wild-type littermates in a mouse model of $\mathrm{MNU}$ and $H$ pylori induced gastric cancer formation. We found that lack of iNOS significantly lowered the incidence of $H$ pylori associated gastric cancer. These data suggest chronic iNOS overexpression and consequent NO overproduction may principally contribute to $H$ pylori induced gastric carcinogenesis. These observations suggest that amelioration of $\mathrm{NO}$ production might be a
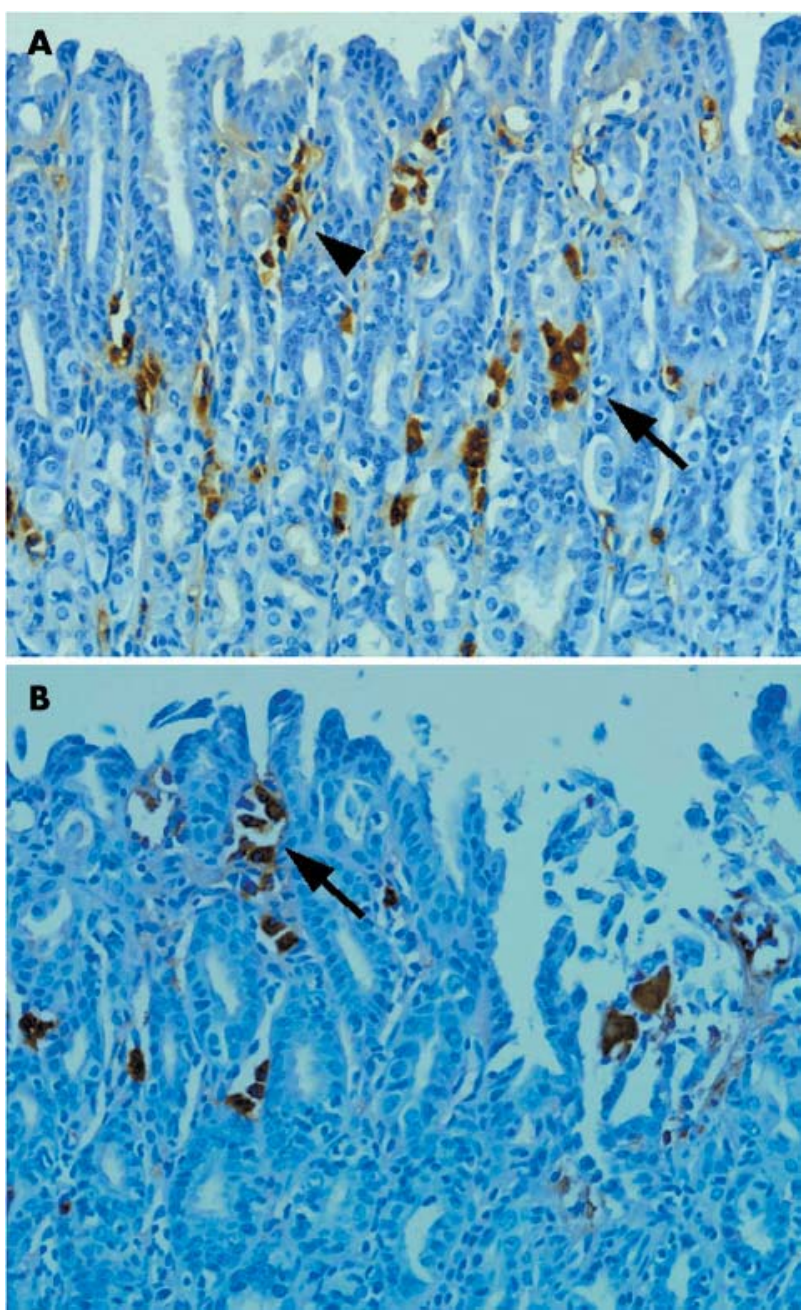

Figure 4 Immunohistochemical staining for 3-nitrotyrosine in inducible nitric oxide synthase (iNOS) wild-type mice with gastritis (A) and adenoma (B). (A) 3-Nitrotyrosine protein was located primarily in the cytoplasm of inflammatory cells such as macrophages (arrow) and some fibroblasts (arrowhead) in the area of foveolar epithelial hyperplasia (original magnification $\times 200$ ). (B) 3-Nitrotyrosine protein was located primarily in the cytoplasm of fibroblasts (arrow) in the area of the lamina propria of adenoma lesions (original magnification $\times 200$ ). 

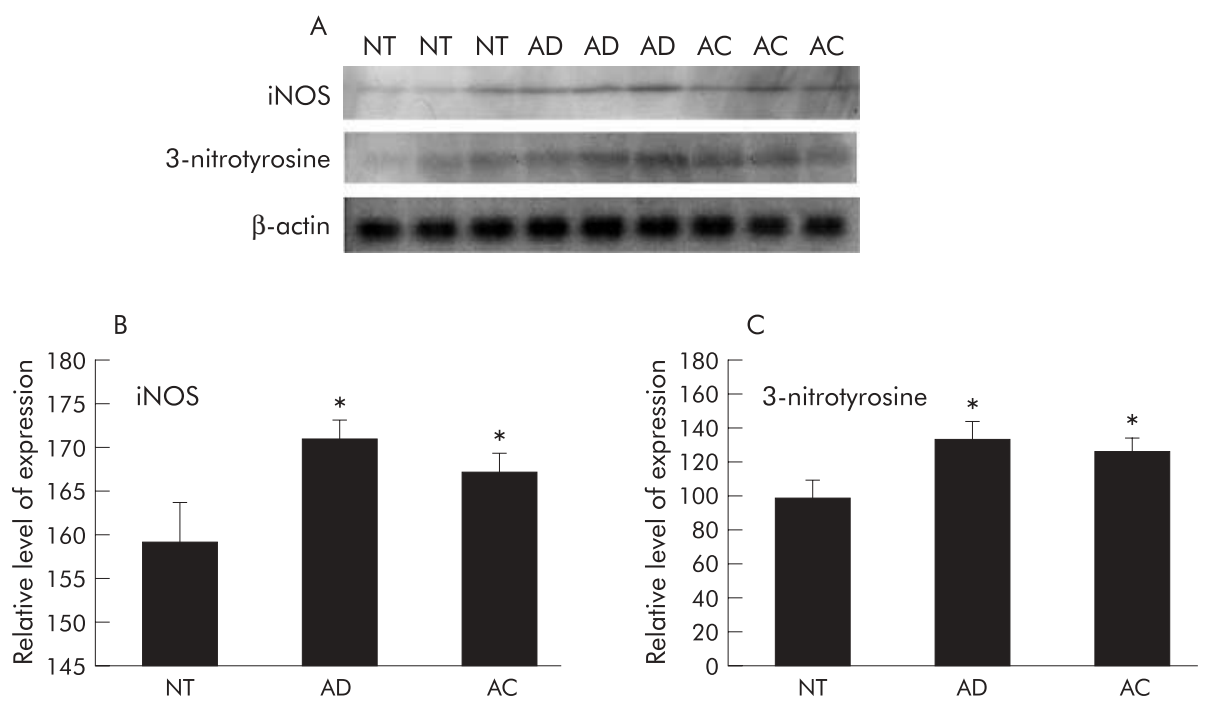

Figure 5 Inducible nitric oxide synthase (iNOS) and 3-nitrotyrosine protein expression levels in tumours and non-tumour tissues in wild-type mice. iNOS and 3-nitrotyrosine protein expression levels were determined by western blot analysis. Mean (SEM) values are shown. (A) iNOS and

3-nitrotyrosine proteins were identified in non-tumour (NT), adenoma (AD), and adenocarcinoma (AC) tissue homogenates from wild-type mice. (B) iNOS expression was significantly higher in $A D$ and $A C$ compared with NT tissues $(p<0.05)$. (C) The amount of 3 -nitrotyrosine protein in $A D$ and $A C$ tissue homogenates was significantly higher than that in NT tissues ( $\left.{ }^{*} p<0.05\right)$.

feasible chemoprevention strategy for $H$ pylori associated gastric carcinogenesis.

Chronic inflammation provides a microenvironment that can drive tumorigenesis. ${ }^{521}$ The incidence of gastric cancer has been mechanistically and clinically associated with $H$ pylori infection induced chronic gastritis. Recent studies ${ }^{12} 22$ have revealed that $H$ pylori infection in humans is associated with enhanced expression of iNOS by tissue neutrophils and mononuclear cells, and that NO and its products are key molecules in $H$ pylori pathophysiology. There has been accumulating evidence that high levels of NO sustained over extended periods of time contribute to carcinogenesis.

The toxicity of NO has been attributed to the potent nitrating and oxidising agent, peroxynitrite, which is formed by a near diffusion limited reaction between NO and superoxide. Peroxynitrite has been shown to induce DNA strand breaks, provoke nitration and oxidation of proteins and nucleic acids, and drive cell death in vitro. ${ }^{2324}$ As there is no suitable method to directly detect peroxynitrite formation in vivo, its reaction product, 3-nitrotyrosine, is measured as a marker of peroxynitrite production. This product has been detected immunohistochemically in acute lung injury in humans and rats, ${ }^{25}$ and in liver tumours. ${ }^{26}$

In the present study, expression and location of 3-nitrotyrosine were investigated immunohistochemically in $H$ pylori associated gastric tumours. It was anticipated that absence of iNOS would lower peroxynitrite levels, and consistent with this, we observed positive staining for 3-nitrotyrosine only in tissue from wild-type mice. 3-Nitrotyrosine in stomach tumours was localised primarily in stromal cells with no detectable staining of the epithelium, which was characterised by a strong intense cytoplasmic staining pattern. 3-Nitrotyrosine positive cells (most likely inflammatory cells) were observed in mesenchymal tissues of gastritis and gastric adenoma samples, and were also observed in cells of venules and arterioles. These results are consistent with those of Goto and colleagues ${ }^{12}$ who observed nitrotyrosine in inflammatory cells and the extracellular matrix of human gastric cancer samples. Epithelial staining and intense staining in areas of intestinal metaplasia were consistent with epithelial localisation of iNOS in human $H$ pylori gastritis ${ }^{27}$ and inflammatory bowel disease. ${ }^{28}$ The present study demonstrated that iNOS is expressed principally in epithelial cells of adenocarcinoma tissues. Epithelial staining was particularly strong in glands exhibiting intestinal metaplasia. Quantitative analysis of iNOS and 3-nitrotyrosine expression in wild-type mice showed adenoma tissues had the highest levels of iNOS and 3-nitrotyrosine compared with non-tumour and adenocarcinoma tissue. These data suggest that iNOS and 3-nitrotyrosine may play an important role in the early stage initiation of gastric carcinogenesis.

Chronic inflammatory diseases of the gastrointestinal tract thought to precede cancer include Barrett's oesophagus, ulcerative colitis, and $H$ pylori associated gastritis, and all are associated with increased iNOS expression and considerable nitrosative stress. ${ }^{58}$ These observations suggest chronic overexpression of iNOS, and the associated NO overproduction may contribute to tumorigenesis, making this process an attractive target for chemoprevention strategies. iNOS-/mice are reported to have a significant resistance to lethality, and show attenuated colonic damage and reduced nitrotyrosine formation and malondialdehyde concentrations in the trinitrobenzene sulphate induced ulcerative colitis model. ${ }^{29}$ iNOS - /- mice fed dextran sodium sulphate showed reduced signs and symptoms of colitis compared with wild-type mice, suggesting that iNOS plays a critical role in the pathology of colitis. ${ }^{30}$ However, the implications of this reduced inflammation on the development of colon cancer in these mice has not been shown. Ahn and Ohshima ${ }^{13}$ reported a significant reduction in the number of adenomas in Min/iNOS ${ }^{-1-}$ mice compared with Min (multiple intestinal neoplasia) mice, indicating NO plays a key role in promoting colon carcinogenesis on a background of an APC mutation. The current study appears to be the first showing the preventive effect of iNOS genetic ablation on $H$ pylori associated gastric carcinogenesis.

In contrast with our findings, some studies have shown either no effect or even exacerbation of inflammation and tumorigenesis following NO inhibition. In a Rhesus monkey model, Ribbons and colleagues ${ }^{16}$ found no effect of the NO inhibitor aminoguanidine (AG) on spontaneous colitis, and Yoshida and colleagues ${ }^{17}$ reported that inhibition of $\mathrm{NO}$ production by either $1-\mathrm{N}(\mathrm{G})$-nitroarginine methyl ester or AG 
resulted in increased dextran sodium sulphate induced inflammation, suggesting a protective role of NO in a disease model of acute colitis. We found that administration of AG to $H$ pylori infected animals did not significantly decrease the incidence of $H$ pylori promoted gastric carcinogenesis or the severity of $H$ pylori associated gastritis (unpublished data). Therefore, we inferred that AG alone did not affect the significant attenuation of iNOS or insufficient ablation of iNOS expression compared with the current genetic ablation. The other possibility is that insufficient blocking or inappropriate blocking time of iNOS was achieved after AG treatment, which rather blocked the beneficial role of NO in either inflammation or carcinogenesis.

In conclusion, we found that $H$ pylori induced gastric tumorigenesis and NO associated nitrotyrosine formation related to carcinogenesis was lower in mice lacking iNOS. Therefore, lowering of iNOS derived NO levels may be an important clinical strategy in the prevention of $H$ pylori associated gastric cancer.

\section{ACKNOWLEDGEMENTS}

This study was supported by a grant from the Korean Health 21 R\&D Project, Ministry of Health \& Welfare, Republic of Korea (02-PJIPG3-20802-0014), and by the Brain Korea 21 Project. We also thank the Korea Food and Drug Administration for partial support.

\section{Authors' affiliations}

K T Nam, B Ahn, D D Jang, K-H Yang, Department of General

Toxicology, National Institute of Toxicological Research, Korea Food and Drug Administration, Seoul, Korea

S-Y Oh, D-Y Kim, Department of Veterinary Pathology, College of Veterinary Medicine and School of Agricultural Biotechnology, Seoul National University, Seoul, Korea

Y B Kim, K-B Hahm, Genome Research Centre for Gastroenterology, Ajou University School of Medicine, Suwon, Korea

\section{REFERENCES}

1 Parkin DM, Laara E, Muir CS. Estimates of the worldwide frequency of sixteen major cancers in 1980. Int J Cancer 1998;41:184-97.

2 Ahn YO, Park BJ, Yoo KY, et al. Incidence estimation of female breast cancer among Koreans. J Korean Med Sci 1994;9:328-34.

3 Blaser MJ, Chyou PH, Nomura A. Age at establishment of Helicobacter pylori infection and gastric carcinoma, gastric ulcer, and duodenal ulcer risk. Cancer Res 1995;55:562-5

4 IARC Working Group on the Evaluation of Carcinogenic Risks to Humans. Helicobacter pylori. In: Schistosomes, liver flukes and Helicobacter pylori: Views and expert opinions of IARC Working Group on the Evaluation of Carcinogenic Risks to Humans. Lyon: IARC, 1994:177-240.

5 Ohshima H, Bartsch $\mathrm{H}$. Chronic infections and inflammatory processes as cancer risk factors: possible role of nitric oxide in carcinogenesis. Mutat Res 1994;305:253-64.

6 Nathan C, Xie QW. Nitric oxide synthases: roles, tolls, and controls. Cell 1994;78:915-18.
7 Jenkins DC, Charles IG, Thomsen $L$, et al. Roles of nitric oxide in tumor growth. Proc Natl Acad Sci U S A 1995;92:4392-6.

8 Doi K, Akaike T, Horie H, et al. Excessive production of nitric oxide in rat solid tumor and its implication in rapid tumor growth. Cancer 1996;77:1598-604.

9 Feng CW, Wang LD, Jiao $\mathrm{LH}$, et al. Expression of $\mathrm{p} 53$, inducible nitric oxide synthase and vascular endothelial growth factor in gastric precancerous and cancerous lesions: correlation with clinical features. BMC Cancer 2002;2:8.

10 Rajnakova A, Moochhala S, Goh PM, et al. Expression of nitric oxide synthase, cyclooxygenase, and p53 in different stages of human gastric cancer. Cancer Lett 2001;172:177-85.

11 Antos D, Enders G, Rieder G, et al. Inducible nitric oxide synthase expression before and after eradication of Helicobacter pylori in different forms of gastritis. FEMS Immunol Med Microbiol 2001;30:127-31.

12 Goto T, Haruma K, Kitadai Y, et al. Enhanced expression of inducible nitric oxide synthase and nitrotyrosine in gastric mucosa of gastric cancer patients. Clin Cancer Res 1999;5:1411-15.

13 Ahn B, Ohshima H. Suppression of intestinal polyposis in $\mathrm{Apc}^{\mathrm{Min} /+}$ mice by inhibiting nitric oxide production. Cancer Res, 2001;61, 8357-60.

14 Okamoto T, Masuda Y, Kawasaki T, et al. Aminoguanidine prevents concanavalin A-induced hepatitis in mice. Eur J Pharmacol 2000;396: 125-30.

15 Yasuhiro T, Korolkiewicz RP, Kato S, et al. Role of nitric oxide in pathogenesis of serotonine-induced gastric lesions in rats. Pharmacol Res 1997;36:333-8.

16 Ribbons KA, Currie MG, Connor JR, et al. The effect of inhibitors of inducible nitric oxide synthase on chronic colitis in the rhesus monkey. J Pharmacol Exp Ther 1997; 280:1008-15.

17 Yoshida Y, Iwai A, Itoh K, et al. Role of inducible nitric oxide synthase in dextran sulphate sodium-induced colitis. Aliment Pharmacol Ther 2000;14:26-32.

18 MacMicking JD, Nathan C, Hom G, et al. Altered responses to bacterial infection and endotoxic shock in mice lacking inducible nitric oxide synthase. Cell 1995:81:641-50

19 Han SU, Kim YB, Joo HJ, et al. Helicobacter pylori infection promotes gastric carcinogenesis in a mice model. J Gastroenterol Hepatol 2002;17:253-61.

20 Leininger JR, Jokinen MP. Tumours of the oral cavity, pharynx, oesophagus and stomach. In: Turusov VS, Mohr U, eds. Pathology of tumours in laboratory animals. Lyon: IARC, 1994:167-93.

21 O'Byrne KJ, Dalgleish AG. Chronic immune activation and inflammation as the cause of malignancy. Br J Cancer 2001;85:473-83.

22 Mannick EE, Bravo LE, Zarama G, et al. Inducible nitric oxide synthase, nitrotyrosine, and apoptosis in Helicobacter pylori gastritis: effect of antibiotics and antioxidants. Cancer Res 1996;56:3238-43.

23 Beckman JS, Koppenol WH. Nitric oxide, superoxide, and peroxynitrite: the good, the bad, and ugly. Am J Physiol 1996;271:C1424-37.

24 Ischiropoulos $\mathrm{H}$, al-Mehdi $A B$. Peroxynitrite-mediated oxidative protein modifications. FEBS Lett 1995;364:279-82.

25 Haddad IY, Pataki G, Hu P, et al. Quantitation of nitrotyrosine levels in lung sections of patients and animals with acute lung injury. J Clin Invest 1994:94:2407-13.

26 Ahn B, Han BS, Kim DJ, et al. Immunohistochemical localization of inducible nitric oxide synthase and 3-nitrotyrosine in rat liver tumors induced by $\mathrm{N}$-nitrosodiethylamine. Carcinogenesis 1999;20:1337-44.

27 Fu S, Ramanujam KS, Wong A, et al. Increased expression and cellular localization of inducible nitric oxide synthase and cyclooxygenase 2 in Helicobacter pylori gastritis. Gastroenterology 1999;116:1319-29.

28 Singer II, Kawka DW, Scott S, et al. Expression of inducible nitric oxide synthase and nitrotyrosine in colonic epithelium in inflammatory bowel disease. Gastroenterology 1996;111:871-85.

29 Zingarelli B, Szabo C, Salzman AL. Reduced oxidative and nitrosative damage in murine experimental colitis in the absence of inducible nitric oxide synthase. Gut 1999;45:199-209.

30 Krieglstein CF, Cerwinka WH, Laroux FS, et al. Regulation of murine intestinal inflammation by reactive metabolites of oxygen and nitrogen: divergent roles of superoxide and nitric oxide. J Exp Med 2001;194:1207-18. 